\title{
Mot de la direction
}

La Revue Organisations et territoires et fier de vous proposer ce numéro spécial sur la région de l'Outaouais coordonné par le professeur Guy Chiasson et Mme Chantale Doucet de l'Université du Québec en Outaouais. Le caractère transfrontalier avec la province de l'Ontario confronte la région de l'Outaouais à des défis socioéconomiques différents des autres régions du Québec. De plus, les disparités importantes des MRC de cette région amènent à une grande diversité des questionnements scientifiques sur une région transfrontalière qui connaît deux dynamiques différentes.

L'objectif de ce numéro est donc de présenter les diverses stratégies et pratiques pour animer le développement et l'innovation en Outaouais dans ce contexte. Le numéro rassemble un éditorial et neuf contributions importantes dont vous apprécierez la qualité des analyses et des réflexions critiques sur les dynamiques et pratiques territoriales.

Nous profitons de ce mot pour vous annoncer une nouvelle direction et la mise en place du comité d'orientation et du comité rédaction de la revue. Conscient des nombreux défis à relever dans le cadre de ce mandat, nous visons le maintien et le prolongement de la qualité du travail déjà réalisé sous la direction du professeur Brahim Medebb.

Bonne lecture!

\section{Thierno Diallo \\ Directeur \\ Revue Organisations et territoires}

